\title{
Mejoramiento de los parámetros en la elaboración de una bebida fermentada de sorgo símil cerveza
}

\section{Parameters improvement in the brewing process with unmalted} sorghum

\section{Doctorando:}

\author{
Ing. Laura Cecilia Gómez Pamies \\ Universidad Tecnológica Nacional Facultad Regional Resistencia \\ lauragomezpamies@hotmail.com
}

\section{Director/es:}

Dra. Ing. Elisa Inés Benítez

\begin{abstract}
Resumen
En el uso de granos alternativos para elaborar bebidas fermentadas para personas celíacas, como el sorgo, puede partirse de granos malteados o sin maltear. Aquí se presentan los estudios realizados a sorgo sin maltear para lograr la disminución de taninos del grano y mejorar el desarrollo de FAN (Free Amino Nitrogen) del mosto durante el macerado. El proceso de elaboración de esta bebida consiste en un pretratamiento de los granos, constituido por etapas de sanitización, extracción de taninos y tratamiento químico. Luego un proceso de decocción que permite la gelatinización del almidón y, a continuación, el proceso de maceración con escalones de temperatura y el uso de dos enzimas exógenas, amilasa y papaína. El sorgo (Sorghum bicolor) de la región nordeste de Argentina se caracteriza por su alto contenido en taninos, que, en el proceso de elaboración de la bebida, se unen a las enzimas alfa-amilasa y limitan su acción durante el macerado. Es por este motivo que se debe reducir la concentración de taninos para no comprometer el rendimiento del proceso.

Para esto, se realizó una primera extracción con agua caliente y luego pretratamientos durante 2 y 4 días con soluciones diluidas de hidróxido de sodio $0,1 \%$, hipoclorito de sodio 0,5\% y agua destilada como blanco. El acondicionamiento durante 4 días se realizó sin cambiar las soluciones en el lapso de tiempo propuesto, sin embargo, para el caso de 2 días, se realizó la prueba con y sin recambio de las soluciones cada 12 horas. Se encontró que el procedimiento que logra una mayor reducción de la cantidad de taninos en el sorgo es el pretratamiento con hipoclorito de sodio durante 4 días.

Para mejorar los niveles de FAN del mosto se realizó un diseño experimental con dos concentraciones de alfa amilasa ( 2 y $3 \%$ en peso de granos secos), tres concentraciones de papaína $(0,5 ; 1$ y $1,5 \mathrm{~g} / \mathrm{kg}$ de sorgo seco) y también en ausencia total de enzimas. El análisis estadístico indica que existe un efecto de interacción entre las enzimas durante la maceración. Se encontró un valor máximo de FAN de 11,39mgN/l con el uso de 1,5g/kg de papaína y 3\% de alfa amilasa $(\mathrm{p}<0,05)$, sin embargo, aún este valor de FAN no es suficiente para una correcta fermentación del mosto. Esto puede deberse a la interacción de las enzimas durante el proceso, insuficiente cantidad de las mismas o baja gelatinización del almidón.
\end{abstract}




\begin{abstract}
In using alternative grains in brewing for people with celiac disease, such as sorghum, malted or unmalted grains could be used. Here, studies using unmalted sorghum aimed to reduce grain tannins and improve wort FAN (Free Amino Nitrogen) development during mashing are presented. The brewing process starts with a pretreatment of the grains, which consists in sanitization, tannin extraction and chemical treatment. This is followed by a decoction, which enables gelatinization of the starch to proceed, and then the mashing process using temperature steps and the addition of two exogenous enzymes, amylase and papain. Sorghum (Sorghum bicolor) of the northeast region in Argentina is characterized for its high tannin content. Compounds which are able to bind amylase enzymes in the brewing process, limiting their action during mashing. For this reason, it is necessary to reduce tannin concentration in order to not compromise the process performance.

For this purpose, a first extraction using hot water was made followed by pretreatments during 2 and 4 days with dilute solutions of sodium hydroxide $0,1 \%$, sodium hypochlorite $0,5 \%$ and distillate water as control. The 4 -days conditioning was made without solvent replacement. However, the 2-days pretreatment process was made with and without solvent replacement every 12 hours. It was found that the procedure with sodium hypochlorite during 4 days was the one that achieves the best tannin reduction.

In order to improve FAN levels, an experimental design using two concentrations of alpha amylase $(2$ and $3 \%$ of dry grain weight), three concentrations of papain $((0,5 ; 1 \mathrm{y} 1,5 \mathrm{~g} / \mathrm{kg}$ dry sorghum) and no enzymes (control), was performed. The statistical analysis indicates an interaction effect between enzymes during mashing. The maximum FAN value was $11,39 \mathrm{mgN} / \mathrm{l}$, using $1,5 \mathrm{~g} / \mathrm{kg}$ papain and $3 \%$ alpha amylase $(\mathrm{p}<0,05)$; however, this value is still not enough for a correct fermentation of the wort. This could be due to the interaction of the enzymes during the process, insufficient amount of enzymes, or a poor gelatinization of starch.
\end{abstract}

Keywords: amino acids, tannins, celiac, enzymes.

\title{
Introducción
}

La Celiaquía es una enfermedad autoinmune que actualmente afecta aproximadamente al 1\% de la población del país (Hager, et al., 2014). No tiene cura y solo puede tratarse eliminando el gluten de la dieta del paciente. Debido a que el sorgo es un cereal naturalmente libre de gluten, se plantea el desarrollo de una bebida fermentada símil cerveza a partir de este grano, cuya explotación en la región es prácticamente nula.

La elaboración de bebidas símil cerveza a partir de sorgo sin maltear requiere la utilización de enzimas exógenas y programas específicos de maceración (Holmes, et al., 2017). En este trabajo se presentan los análisis para el mejoramiento de los niveles de FAN (Free Amino Nitrogen) durante el macerado y la reducción de los taninos durante el pretratamiento.

FAN implica la cantidad de nitrógeno de aminoácidos disponibles para las levaduras durante la fermentación (Abernathy, et al., 2009). Para que ésta sea eficiente, se requiere un nivel óptimo de $150 \mathrm{mg} / \mathrm{l}$, mientras que un valor por debajo implica fermentaciones lentas e incompletas y aparición de compuestos indeseados (Dlamini, et al., 2015).

Por otro lado, el sorgo de la región chaqueña se caracteriza por tener alto contenido de taninos, cuya concentración se correlaciona de manera negativa con los azúcares fermentables y FAN en el mosto. Esto se debe a la interacción de los taninos y las enzimas en el macerado, formando complejos irreversibles (Adetunji, et al., 2013). Esto puede ser prevenido con pretratamientos químicos (Adetunji, et al., 2014).

\section{Metodología}

\section{Extracción de polifenoles y taninos}

Los granos de sorgo se sanitizaron con solución de hipoclorito de sodio al 0,5\% durante 30 minutos, luego se extrajeron los taninos añadiendo agua destilada en una relación 3:1 respecto al peso de los granos, y manteniendo a $75^{\circ} \mathrm{C}$ durante 2 horas. Luego se retiró el agua resultante, concentrada en polifenoles y taninos.

\section{Pretratamientos}

Se probaron tratamientos con tres solventes: agua destilada (blanco), hipoclorito de sodio 0,5\% v/v ( $\mathrm{NaClO}$ ) e hidróxido de sodio $0,1 \% \mathrm{p} / \mathrm{v}(\mathrm{NaOH})$, usando una relación 1:1 de muestra húmeda y solvente en cada caso. Para cada solvente se realizaron tres pruebas según la duración el período de tratamiento: 4 días sin recambio de solvente (4d), y durante 2 días sin recambio (2dSR) y con recambio cada 12 horas (2dCR). 


\section{Gelatinización}

A continuación, se realizó el ablandamiento del grano y la gelatinización del almidón, hirviendo las muestras pretratadas con agua destilada en una relación 1:2 durante una hora.

\section{Maceración y cocción}

El sorgo gelatinizado se enfrió hasta $50^{\circ} \mathrm{C}$ y se llevaron las muestras a un baño calefactor de laboratorio para proceder a la maceración. El proceso de macerado se llevó a cabo siguiendo los escalones de tiempo-temperatura descriptos por Ogbonna (Ogbonna, 2011) con algunas modificaciones en las temperaturas de trabajo. Se utilizaron tres escalones: 50 minutos a $50^{\circ} \mathrm{C}, 30$ minutos a $60^{\circ} \mathrm{C}$ y 20 minutos a $70^{\circ} \mathrm{C}$. Al comienzo de la maceración se añadieron las enzimas. Se probaron dos enzimas: alfa amilasa (Alphamalt VC, 5000SKB) en concentraciones del 2 y $3 \%$ en peso y papaína (Biopack, 30000U/mg) en concentraciones de 0,5; 1 y 1,5 g/kg de sorgo. También se probó en ausencia de enzimas.

Luego de la maceración, se filtraron las muestras en tamiz grueso, obteniéndose los mostos, que se llevaron a cocción durante una hora. Al final de la cocción se leyó la concentración de azúcares en grados Brix con refractómetro manual.

Análisis químicos

Se realizaron ensayos de aminoácidos libres (FAN) por el método Mebak (MEBAK, 2013) y de proteínas por el método Bradford (Bradford, 1976) a las muestras de mostos, mientras que a las muestras resultantes de los pretratamientos se les realizaron ensayos de polifenoles mediante el método de Folin-Ciocalteau (Singleton, et al., 1999) y de taninos mediante el método de HCl-Vainillina (Burns, 1971).

\section{Resultados}

Grados brix

Un valor de $10^{\circ} \mathrm{Bx}$ es un estándar de concentración de azúcares en el mosto capaz de brindar un valor aproximado de alcohol 4\% v/v de producto final (Bamforth, 2003). El valor máximo obtenido en el diseño corresponde al uso de las máximas concentraciones de enzimas y es de $3^{\circ} \mathrm{Bx}$. En ninguno de los casos la concentración de azúcares es suficiente, esto puede deberse a una incompleta etapa de gelatinización al comienzo del proceso, lo que no permitió que se hidrolizara el almidón durante la etapa del macerado, al no estar disponible.

\section{FAN}

Según el análisis de la varianza, existe efecto de la interacción entre las dos enzimas $(\mathrm{p}<0,05)$. El de mayor valor obtenido es de $11,39 \mathrm{mgN} / \mathrm{l}$ y diferente significativamente a las demás según el test de Duncan. Sin embargo, todavía se encuentra muy por debajo del nivel óptimo necesario para una correcta fermentación que corresponde a 150mg/l (Dlamini, et al., 2015).

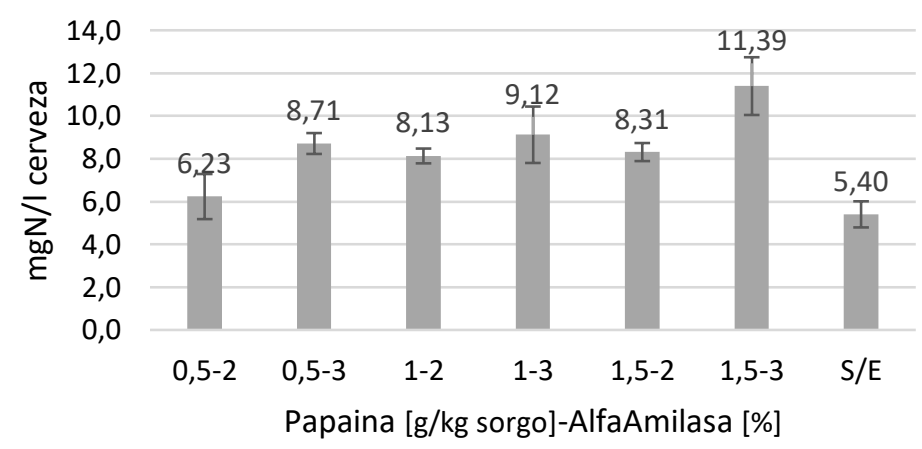

Figura 1. Contenido de FAN en mostos de sorgo utilizando dos enzimas: papaína y alfa amilasa.

\section{Proteínas}

Se puede observar en los resultados un valor muy alto de proteínas en la prueba sin enzimas, que coincide con el menor valor de FAN, ya que, en este caso, las proteínas no se hidrolizan a aminoácidos y péptidos durante la maceración. 


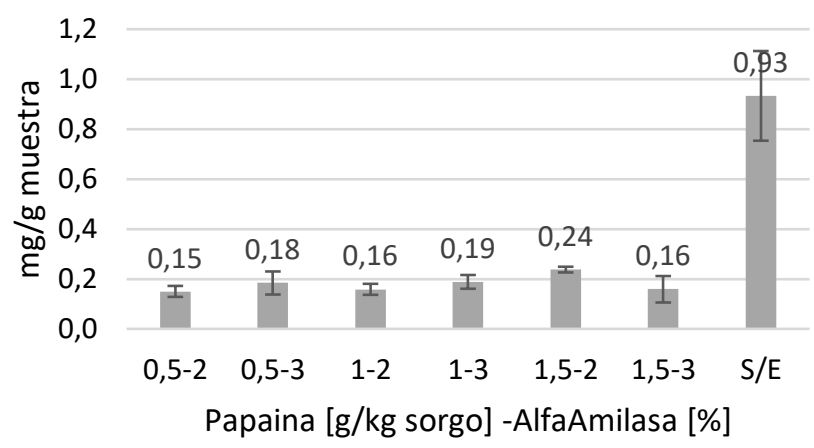

Figura 2. Contenido de proteínas en mostos de sorgo utilizando dos enzimas: papaína y alfa amilasa.

\section{Taninos}

Para todos los solventes, aumenta la extracción de taninos con el número de días de tratamiento y en todos los casos, el hipoclorito de sodio es el solvente que mayor cantidad de taninos extrae. De la prueba con recambio también se puede concluir que la extracción de taninos lleva un tiempo mayor a las 12 horas.

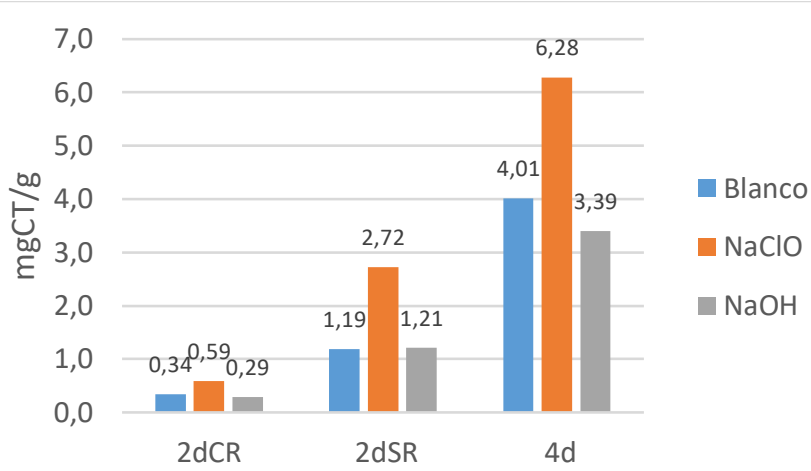

Figura 3. Extracción de taninos con agua destilada (Blanco), hipoclorito de sodio ( $\mathrm{NaClO}$ ) e hidróxido de sodio ( $\mathrm{NaOH}$ ) como solventes para 2 días (con y sin recambio) y 4 días.

\section{Conclusiones}

Si bien el sorgo colorado sin maltear es una buena opción para utilizarse como materia prima en la elaboración de esta bebida, deben utilizarse enzimas exógenas (tanto amilasas como proteasas) para lograr un mosto con parámetros óptimos para una fermentación correcta.

En este trabajo se pudo verificar la importancia de la hidrólisis enzimática durante el macerado para el desarrollo de azúcares fermentables y aminoácidos libres en el mosto obtenido a partir de sorgo sin maltear. Se concluye la importancia, en primer lugar, de una eficiente gelatinización del almidón debido a que si este proceso no es completo se producen mostos muy viscosos, difíciles de trabajar y con poca disponibilidad de proteínas y almidón capaces de ser hidrolizables. Entonces, se debe mejorar inicialmente el proceso de gelatinización para luego ajustar la concentración de enzimas óptima que permitan obtener valores de grados Brix y concentración de FAN para una fermentación completa, correcta y eficiente.

Por otro lado, el alto contenido de taninos del sorgo hace que no sea posible hacer cerveza sin tratamiento para inactivarlos. Si bien el hipoclorito de sodio es el solvente que más taninos logra extraer durante el pretratamiento, se sabe que los oxida dando productos indeseables para el color de la cerveza, por lo tanto, el hidróxido de sodio es un buen solvente para un pretratamiento ya que mantiene la capacidad antioxidante de los polifenoles en solución mientras que polimeriza los taninos evitando que interfieran con proteínas.

\section{Agradecimientos}

Se agradece al Consejo Nacional de Investigaciones Científicas y Técnicas (CONICET) y a la Universidad Tecnológica Nacional Facultad Regional Resistencia por el apoyo financiero para realizar las investigaciones. 


\section{Referencias}

Abernathy, D., Spedding, G. \& Starcher, B., 2009. Analysis of Protein and Total Usable Nitrogen in Beer and Wine Using a Microwell Ninhydrin Assay. Journal of the Institute of Brewing, pp. 122-127.

Adetunji, A., Duodu, K. \& Taylor, J., 2014. Inactivation of tannins in milled sorghum grain through steeping in dilute $\mathrm{NaOH}$ solution. Food Chemistry, pp. 225-232.

Adetunji, A., Khoza, S., De Kock, H. \& Taylor, J., 2013. Influence of sorghum grain type on wort physico-chemical and sensory quality in a whole-grain in commercial enzyme mashing process. Journal of the institute of brewing, pp. 156163.

Bamforth, C., 2003. Beer: tap into the art and science of brewing. 2da ed. New York, USA: Oxford.

Bradford, M., 1976. A rapid and sensitive method for the quantitation of microgram quantities of protein utilizing the principle of protein-dye binding. Analytical Biochemistry, pp. 248-254.

Burns, R., 1971. Method for estimation of tannin in grain sorghum. Agronomy Journal, pp. 511-512.

Dlamini, B., Buys, E. \& Taylor, J., 2015. Effect of sorghum type and malting on production of free amino nitrogen in conjunction with exogenous protease enzymes. Journal of the Science of Food and Agriculture, pp. 417-422.

Holmes, C., Casey, J. \& Cook, D., 2017. Mashing with unmalted sorghum using a novel low temperature enzyme system: Impacts of sorghum grain composition and microstructure. Food Chemistry, pp. 324-334.

MEBAK, 2013. Wort, Beer, Beer-based beverages. Freising-Weihenstephan: s.n.

Ogbonna, A., 2011. Current development in malting and brewing trials with sorghum in Nigeria: a review. Journal of the Institute of Brewing, pp. 394-400.

Singleton, V., Orthofer, R. \& Lamuela-Raventos, R., 1999. Analysis of total phenols and other oxidation substrates and antioxidants by means of Folin Ciocalteau reagent. Methods in Enzymology, pp. 152-178. 